\section{A REPORT ON}

\section{CYCLING IN HEALTH AND DISEASE.}

]SPecially PREPaRed for the British Medical JoUrnal.]

By E. B. Turner, F.R.C.S.

IX.-CYCLING ACCIDENTS.

Their Character, Causes, and How to Avoid Them.

Crcling accidents may be divided into two classes-those which depend on the fault of the rider and those which do not.

Faulty Riding.

In the first category come all those "smashes" which are caused by the ignorance or foolhardiness of the bicyclist who allows his machine to get the better of him on a hill which he does not know. No one should ever allow himself to travel at more than five or six miles an hour descending any incline, however easy the gradient may appear, unless he can see the road clear to the bottom, and that no side lanes open into it, and that there is no sudden or abrupt turn. This rule should be absolute, whether a brake be attached to the bicycle or whether the rider, being an expert, trusts to his powers of "back pedalling" to control his pace. The greater number of dangerous hills on the main roads, and on many by-roads also, are safeguarded at the top by a warning notice board placed there by the National Cyclists Union or the Cyclists Touring Club, and riders ignorant of the locality should always on seeing this be prepared to dismount and walk. More accidents are due to reckless riding down hills than to any other cause. Street riding through traffic is also a prolific source of accident. It is full of risk even to the practised, and in the case of the hundreds of novices who may now be seen daily courting destruction under the noses of the horses in London and other large towns it is simply criminal. The same remark applies to those who are foolish enough to ride "hands off." It is the easiest thing in the world to do, and, when indulged in for the purpose of silly display, is often the cause of a very bad fall. Any large stone, grating, or inequality in the road meeting the front wheel while swinging free causes it to be deflected from its true path, and the rider must then come to earth, face first.

Many accidents are also due to the fault-a common oneof not making sure that every nut and bolt in the machine is properly screwed up and in order before starting. It is especially important to be careful about this when the bicycle is new. For the first few rides it is "finding itself," and a spanner should always be put on every essential nut, and, if visible, the lock-nut of the chain, until the parts have properly shaken together.

\section{Faulty Machines.}

The accidents which are not due to the fault of the rider generally are caused by the sudden failure of some important part of the machine. This may be due to an unseen and undetected flaw in the metal-rare in the highest class of bicycles, but more or less frequent in those of the cheap description. Nothing can guard against this, except to take every precaution, and only use the goods of a firm which has a reputation to lose.

Early Eccentrieities.

It is not necessary to treat of the mishaps of beginners until it be mastered the bicycle has a miraculous gift of throwing its owner in the most unexpected fashion, and of running into every obstacle that lies in or near the road. This last eccentricity is easily explained by the fact that the steering follows the sight automatically, and a novice on wheels always intently regards that which he should avoid.

$$
\text { "Side Sirip." }
$$

"Side slip" depends partly on the rider, and partly on an unavoidable combination of circumstances. If when the roads are "greasy" great care is exercised, and the machine kept upright and very steady at a moderate pace, it is often possible to escape without a slip, but sometimes even the most careful come to grief at a moment's notice. This is caused by the inflated tyre floating on the surface of the gluey mud, and never really getting a grip of the road surface, and if the road be " hogged," or the rider attempt an abrupt turn, the wheel slides away from under him, and he falls sideways without the slightest warning. There are many patent tyre covers invented for the purpose of avoiding this accident, but when the surface is really bad they are all equally useless, though when the conditions are less unfavourable they all have a certain good effect. A reckless, unskilful rider with bad "ankle action" can hardly escape disaster if he ride over "grease" at a fast pace. It is evident that a fall from this cause in front of an omnibus may very easily prove fatal, as the driver of the vehicle has no time to pull up. On a country road, though unpleasant, it is not often attended with serious injury. A fall sometimes results from an air tyre bursting and blowing off the rim of the wheel, which then collapses under the weight of the rider. This is more frequent in racing than in road riding. Many falls are caused by collisions with pedestrians, carts, cabs, and other conveyances. The exercise of due care will generally avoid an accident from these causes, but drunken and evil disposed drivers still exist who think it good sport to run down a cyclist. Judicious prosecution has of late years much reduced their numbers.

\section{Fractures: "The Cycle Graze."}

The injuries sustained from cycle accidents do not differ in any essential particular from those caused by other falls from swiftly moving carriages. The knees most frequently suffer, and the collar-bone is most often fractured-the fracture being in a large number of cases of the " green-stick" variety. Anyone falling and hurting the knee should at once cease from riding until it is quite recovered. Much mischief has often ensued from riding home with an apparently slightly injured knee-joint. The "cycle graze" is very troublesome to heal. The two upper layers of the skin over some bony prominence are killed by the blow from the fall, and the resulting sore, if neglected, often remains open for weeks. Antiseptics at the time, and if possible some drying application afterwards, so that healing may take place under a scab, produce the best results. Always be careful that all the grit and dirt are washed out. Hæmatomata occur, and sometimes suppurate, from what seems a very slight cause, but the victim in such cases was probably travelling at a faster pace than he imagined. The directions for avoiding cycle accidents are few and simple. Be sure that, so far as you can ascertain, your bicycle is sound and in good order, and ride it with due care.

\section{LITERARY NOTES.}

THE Boston Medical and Surgical Journal publishes the following interesting letter written to Edward Jenner by Thomas Jefferson:

Monticello, Virginia, May 14th, 1806. 作 of the vaccine inoculation, which you have been pleased to send me, and for which I return you my thanks. Having been among the early converts in this part of the globe to its efficacy, I took an early part in recommending it to my countrymen. I avail myself of this occasion to render you my portion of the tribute of gratitude due to you from the whole human family.

Medicine has never before produced any single improvement of such utility. Harvey's discovery of the circulation of the blood was a beautifu addition to our knowledge of the ancient economy; but on a review of the practice of medicine before and since that epoch, I do not see any ( great amed from the chentest Yours is the comfortable reflection that mankind can never forget that Yours have lived; future nations will know by history only that the loathyou have live fured some small-pox has existed, and by you has been extirpated. Accept the most fervent wishes for your health and happiness, and

We have received the first and second fasciculi of the Mémoires et Bulletins de la Société de Médecine et de Chirurgie de Bordeaux. It comprises the proceedings of the Society for the first half of 1895 . It contains a large number of valuable clinical papers which may be consulted with advantage.

It is announced that the extremely valuable collection of books, manuscripts, and prints relating to American history made by Dr. Thomas Addis Emmet is to be added to the New York Public Library, but to be kept together and called the Emmet Library. Dr. Emmet's public spirit in thus placing at the disposal of the public the fruits of a life-long labour of love cannot be too highly commended. 